\title{
SACCADIC MOVEMENTS USING EYE-TRACKING TECHNOLOGY IN INDIVIDUALS WITH AUTISM SPECTRUM DISORDERS
}

\author{
Pilot study
}

\author{
Marcos T. Mercadante, Elizeu C. Macedo, Patrícia M. Baptista, \\ Cristiane S. Paula, José S. Schwartzman
}

\begin{abstract}
Objective: To verify diff e rences in the visual scanning strategies between pervasive developmental disorders (PDD) and controls when they are observing social and non-social pictures. Method: PDD group (PDDG) comprised by 10 non-ret a rdedsubjects (age from 4 to 41) and age-matched control group (CG). Nine social pictures with human beings (including two pictures of cat mask), and 3 nonsocial pictures of objects were presented for 5 seconds. Saccadic movements and fixation were recorded with equipment EyeGaze ${ }^{\circledast}$ (LC Technologies Inc.). Results: PDDG (mean=292.73, SE=67.62) presented longer duration of saccadic movements for social pictures compared to CG (mean=136.06, SE=14.01) $(p=0.04)$. The CG showed a higher number of fixations in the picture 7 (a women using a cat mask, with the eyes erased) (CG: mean=3.40; PDDG: mean=1.80; $p=0.007$ ). Conclusion: The results suggest diff e rences in strategies that PDD explore human picture. Moreover, these strategies seem not to be affected by the lack of expected part of the face (the eyes).
\end{abstract}

KEY WORDS: autism, Asperger's syndrome, pervasive development disorder, eye movement.

\begin{abstract}
Movimentos sacádicos de indivíduos do espectro autista por varredura visual: estudo piloto
RESUMO - Objetivo: Verificar diferenças nas estratégias de varredura visual de indivíduos com transtorno invasivo do desenvolvimento (TID) comparados a controles normais na observação de figuras sociais e não sociais. Método: Estudo caso-controle. Grupo TID: dez sujeitos com TID, inteligência normal e idade entre 4 e 41 anos; Grupo Controle: dez sujeitos pareados por idade. Os sujeitos observaram por 5 segundos 9 figuras de seres humanos e 3 figuras de objetos. Os movimentos sacádicos e o número de fixações foram gravados em equipamento EyeGaze ${ }^{\circledast}$ (LC Technologies Inc.). Resultados: O grupo TID apresentou maior duração dos movimentos sacádicos na observação de figuras humanas [TID=292,73 (EP=67,62); controle= $136,06(E P=14,01) ; p=0,04]$. $O$ grupo controle apresentou maior número de fixações na figura 7 (mulher com máscara de gato sem os olhos) ( $T I D=1,8$; controle=3,4; $p=0,007$ ). Conclusão: Indivíduos com TID parecem utilizar estratégias diferentes para explorar figura humana. Além disso, o padrão de investigação deles não se modifica quando observam uma figura que rompe com o esperado (a falta dos olhos).
\end{abstract}

PALAVRAS-CHAVE: autismo, síndrome de Asperger, transtornos globais do desenvolvimento infantil, movimento ocular.

Autism is a complex neurodevelopmental disorder affecting social, communication and behavior domains'. Today, the researches have shown that more than a unique entity, autism is a segment of a broad spectrum, comprising by diffe rent penasive developmental disorders (PDD)2. At least, two major issues might be underlying this field; the search for earlier diagnoses and better endophenotypes characterization $^{3,4}$.

Several studies, based on eye tracking devices techniques, have explored the diff e rences between PDD and normal controls gaze strategies in observing human faces ${ }^{5-12}$. The majority of the face perce $p$ tions studies have been focused on visual fixation

\footnotetext{
Pe nasive Developmental Disorder Program, Mackenzie Presbyterian University, São Paulo SP, Brazil. This study was in part supported by MackPesquisa.
}

Received 9 December 2005, received in final form 9 March 2006. Accepted 26 April 2006.

Dr. Marcos T. Mercadante - Rua da Consolação 896 / 62 - 01302-907 São Paulo SP - Brasil. E-mail: mercadante@mackenzie.br 
patterrs. These rese a rches have opened new pathways in developing new diagnostic instruments and in increasing the comprehension of neurobiological bases of PDD ${ }^{13,14}$.

In this study we introduce a new paradigm showing social (human face, as well altered face stimuli we deleted the eyes in a picture of a women using a cat mask) and non-social (objects) stimulus. The goal is to verify differences in the visual scanning strategies, measured by the amount of time spent doing saccadic movements, and the number of fixations, between PDD and controls when they are obsening freely (no-rules, no task oriented) social and non-social pictures. We hypothesize that PDD group $p$ resent more saccadic movement than controls, and this difference is increased by the observation of unexpected pictures.

\section{METHOD}

Sample - A PDD group (PDDG) comprised by 10 nonmental retardation males who met DSM-IV criteria for PDD (age range from 4 to 41 years-old), and an age-matched control group (CG) comprised by 10 males without any psychiatric disorder. All participants were drug free. The PDD diagnoses were done by two psychiatrists with expertise in the field. In addition, the Autism Screening Questionnaire ${ }^{15}$ was applied to all studied cases. Twelve large pictures were showed (full 15" computer screen) for 5 seconds to all participants (pictures available at request to the correspondent author). Six were pictures from human being (close of the face or social situations), two are pictures of a women using a cat mask, but in one of them the eyes were deleted, one is a picture of four masks sculptures, and the last th ree are pictures of draws (a door, a salt cellar, and a dish with a set of cutlery). The pictures were analyzed considering two groups, the group of pictures with a human image stimulus, comprised by the first nine pictures (social pictures), and the group of pictures without human stimulus, comprised by the last three pictures (non-social pictures). The study was approved by the ethics committee of Mackenzie Presbyterian University. All the subjects or their parent were informed about the procedures read and signed the informed consent.

Procedure - The subjects were sited in front of a computer ( $50 \mathrm{~cm}$ from the screen) with an eye-tracking device, and asked to watch. They already knew that no questions would be done, and the only task was to watch some pictures. In addition, they were informed that there were no rules, neither right nor wrong ways to do the task. The eye movements were recorded with equipment EyeGaze ${ }^{\circledR}$ (LC Technologies Inc.) that allows analysis of saccadic movements (mean length and duration) and fixation (localization and duration).

Statistical analysis - Four parameters (mean length of saccadic movement, duration of the saccadic movement,

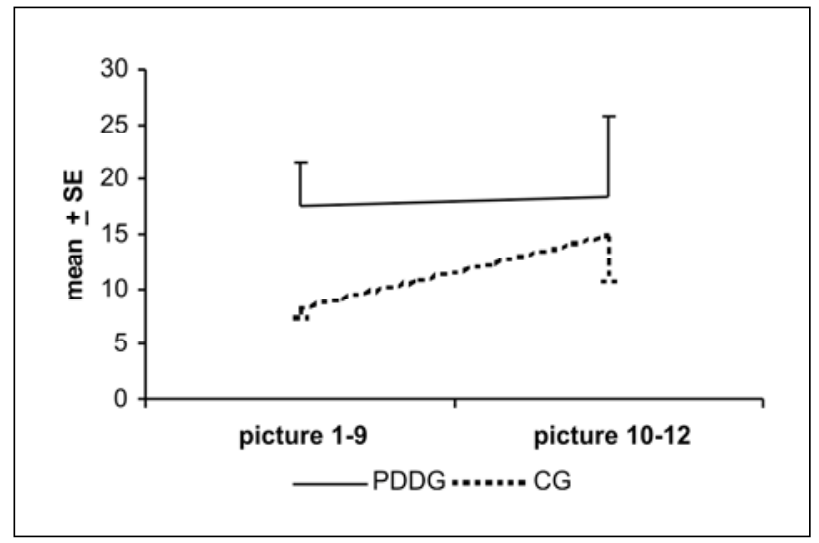

Figure Saccadic movements observing the social and non-social pictures. PDDG: pervasive developmental disorders group; CG: control group; Picture 1-9: social stimulus; Picture 10-12: nonsocial stimulus.

fixation point time, and number of fixations) were analyzed. We also analyzed these variables according five specific regions (eyes region, mouth region, face, out-side of the face and nose). The non-social pictures were only analized as the whole picture. Logarithmic correction was applied to normalize data distribution. The analysis of variance for repetitive measurements were applied. The comparisons we re done by Wald's test. A significance of .05 was considered.

\section{RESULTS}

The PDDG was comprised by 10 non-mental retardation males, mean age of $15.9(\mathrm{SD}=10.6)$ (ages $=4$, $8,8,13,13,11,19,19,23,41$ years old). The CG was comprised by 10 males without psychiatric disorders, mean age of $16.1(S D=10.3)(p=0.97)$. Considering the nine first pictures (social pictures), the amount of time spent (in milliseconds) by PDDG doing saccadic movements was greater than the amount of time spent by CG [PDDG mean=292.73 ms (SE=67.62), CG mean=136.06 ms ( $S E=14.01) ; p=0.04]$. No difference was observed between groups in the last three pictures (non-social pictures) [PDDG mean $=309.56 \mathrm{~ms}$ $(\mathrm{SE}=122.19), \mathrm{CG}$ mean=247.38 ms ( $\mathrm{SE}=70.51) ; \mathrm{p}=0.76$ ]. The PDDG did not show any difference in the amount of time spent doing saccadic movement $(p=0.54)$ when it was compared the nine first pictures (social pictures) with the last three (non-social pictures). On the other hand, the CG showed a higher amount of time doing saccadic movements observing the nonsocial pictures than they did with the social pictures $(p=0.02)$ (Figure).

The mean length of saccadic movement, the fixation point time, and the number of fixations did not show any difference between groups.

Analyzing picture 6 (a woman with a cat mask) 
and 7 (the same picture with the eyes deleted) the PDDG showed greater amount of time spent doing saccadic movements in both pictures compared to CG [picture 6: PDDG mean=320.06 ms (SE=94.52), CG mean=100.02 ms ( $\mathrm{SE}=27.17)$; picture 7: $P D D G$ mean= $283.39 \mathrm{~ms}$ ( $\mathrm{SE}=82.68)$, $\mathrm{CG}$ mean=141.69 ms $(\mathrm{SE}=49.18)$ $(p=0.01)]$.

The amount of number of fixations did not show any diff e rence comparing the both groups observing the region of the eyes in the picture 6 [PDDG mean=1.60 ( $\mathrm{SE}=0.34), \mathrm{CG}$ mean=2.40 ( $\mathrm{SE}=0.37) ; \mathrm{p}=$ 0.18 , but the CG presented a greater number of fixations in this region in the picture 7 [PDDG mean= 1.80 ( $\mathrm{SE}=0.49$ ), CG mean=3.40 ( $\mathrm{SE}=0.52) ; \mathrm{p}=0.007$ ]. When it was compared the number of fixations between picture 6 and 7, the PDDG did not show any diffe rence $(p=0.6538)$, but the $C G$ tended to have more fixations in this region in the picture $7(p=$ 0.077).

\section{DISCUSSION}

Our study showed that PDD patients spend more time doing saccadic movements than controls when obsening freely human pictures; at the same time, the controls spent more time doing saccadic movements observing the non-social pictures than they do when they observe social pictures. In addition, the PDD patients do not show any diffe rence in the amount of time spent doing saccadic movements when they observe human pictures or non human picture s (Figure). These results suggest that the major diff e rence between groups is determined by the way of the controls explore human pictures.

This study also pointed that only the CG presented a diff e rence in the number of fixations in observing the picture in which the eyes were removed, showing that the controls present more fixations than the PDD group. In normal controls, the lack of something expected (the eyes) seems to induce longer investigations, suggesting that the fail in what should be watched, changes the eye tracking strategies. To understand this result we might admit that normal controls would have some presuppositions underlying their gaze pattern, implying in complex cerebral circuitries activations.

If these data were replicated in larger sample size, the re is a clinical relevance for these findings, since we might have the eye-tracking technique as an auxiliary diagnostic instrument. In addition, based on these results we can explore some neurobiological hypotheses that have been proposed for autism
It has been discussed the diffe rent neuronal circuitry pathways involved in the reflexive and volitional saccades ${ }^{16}$. It seems that a group of specialized neurons named V4 neurons, present pre-saccadic activation. These neurons, and their projections to the parietal cortex, the frontal eyes fields and the superior collicullus, the areas would be involved in the oculomotor programming would be regulating the visual scanning ${ }^{17}$. Focusing on autism, it is import a $n t$ to explore if the saccade abnormality are related to an endogenous pathway dysfunction, or due to the impairment in the executive functions described in this disorder ${ }^{18}$.

In this study, we proposed a free (no rules, no structure, no questions) situation, in which individuals had only to watch some pictures. Within this paradigm we decreased the dependence of the volitional saccades (in terms of task-oriented tests of complex spatial working memory and executive control) ${ }^{16}$. Based on this, our data would be suggesting that PDD present impairment in the endogenous pathway, since they do more saccadic movements than the controls. However, one can argue that the diffe rence observed between two groups might be due to diffe rent strategies in visual scanning, meaning diffe rent executive functions patterns. This rationale seems to be reinforing by the results obtained fro $m$ the exploration of the picture without the eyes, when the controls did more fixations, suggesting more complex circuitries involvement.

If this is the sense, it is possible to consider that even in freely observations normal controls apply visual scanning strategies based on presuppositions. On the other hand, it seems that PDD do not work under the same rules, allow us to formulate a metaphor, in which, the normal control tend to see the world by the brain, instead PDD patients tend to see the world by the retina.

Finally, the current hypotheses of the cerebellar and neocortical systems re $g$ arding the neural origin and cognitive basis of behavioral abnormalities in autism can highlighted some etiopathological models ${ }^{19}$. One, tempting to hypothesize would be that due to the lesser amount of time spent in scanning human face, the PDD subjects might have caused impai rment in the circuitries that would be responsible in regulating the capture of human images, the association with the social meaning of these images, through the circuitries oculomotor, cerebellum and amygdale projections neurons ${ }^{20}$.

The limitations of this study is the small sample 
size, the large range of subjects' age, as well as the lack of more complete neuropsychological evaluations. Interestingly, the older PDD subjects were those who closer to normal controls performed the eye gaze. Based on these data, more studies with larg e $r$ samples are required in order to explore the eye gaze technique in detecting earlier PDD diagnoses.

Acknowledgement - The authors thank Dr. Ami Klin for his suggestions.

\section{REFERÊNCIAS}

1. Volkmar FR, Klin A, Siegel B, et al. Field trial for autistic disorder in DSM-IV. Am J Psychiatry 1994;151:1361- 1367.

2. Volkmar FR, Lord C, Bailey A, Schultz RT, Klin A. Autism and pervasive developmental disorders. J Child Psychol Psychiatry 2004;45: $135-170$.

3. Klin A, Jones W, Schultz R, Volkmar F, Cohen D. Defining and quantifying the social phenotype in autism. Am J Psychiatry 2002;159: 895-908.

4. Dawson G, Webb S, Schellenberg GD, et al. Defining the broader phenotype of autism: genetic, brain, and behavioral perspectives. Dev Psychopathol 2002;14:581-611.

5. Boucher J, Lewis V. Unfamiliar face recognition in relatively able autistic children. J Child Psychol Psychiatry 1992;33:843-859.

6. Klin A, Sparrow SS, Bildt A, Cicchetti DV, Cohen DJ, Volkmar FR. A normed study of face recognition in autism and related disorders. J Autism Dev Disord 1999;29:497-507.

7. Schultz RT, Gauthier I, Klin A, et al. Abnormal ventral temporal cortical activity among individuals with autism and A s pe rger syndrome during face discrimination. Arch Gen Psychiatry 2000;57:331-340.

8. Klin A, Jones W, Schultz R, Volkmar F, Cohen D. Visual fixation pat- terns during viewing of naturalistic social situations as predictors of social competence in individuals with autism. Arch Gen Psychiatry 2002;59:809-816.

9. Pelphrey KA, Sasson NJ, Reznick JS, Paul G, Goldman BD, Piven J. Visual scanning of faces in autism. J Autism Dev Disord 2002;32: 249-261

10. van der Geest JN, Kemner C, Verbaten MN, van Engeland H. Gaze behavior of children with pervasive developmental disorder toward human faces: a fixation time study. J Child Psychol Psychiatry 2002; 43:669-678

11. Trepagnier C, Sebrechts MM, Peterson R. Atypical face gaze in autism. CyberPsychol Behavior 2002;5:213-217.

12. Dalton KM, Nacewicz BM, Johnstone T, et al. Gaze fixation and the neural circuitry of face processing in autism. Nature Neurosci 2005; 8:519-526

13. Dawson G, Webb SJ, McPartland J. Understanding the nature of face p rocessing impairment in autism: insights from behavioral and electrophysiological studies. Develop Neuropsychol 2005;27:403-424.

14. Stokstad E. New hints into the biological basis of autism. Science 2001; 294:34-37.

15. Berument SK, Rutter M, Lord C, Pickles A, Bailey A. Autism screening questionnaire: diagnostic validity. Br J Psychiatry 1999;175:444-451.

16. Minshew NJ, Luna B, Sweeney JA. Oculomotor evidence for neocortical systems but not cerebellar dysfunction in autism. Neurology 1999; 52:917-922.

17. Moore T. Shape re presentations and visual guidance of saccadic eye movements. Science 1999;285:1914-1917.

18. Hill EL, Frith U. Understanding autism: insights from mind and brain. PhilosPhilosophical Transactions of the Royal Society of London. Series B, Biological Sciences 2003;358:281-289.

19. Courchesne E, Pierce K. Why the frontal cortex in autism might be talking only to itself: local over-connectivity but long-distance disconnection. Cur Op Neurobiol 2005;15:225-230.

20. Wang X, Jin J, Jabri M. Neural network models for the gaze shift system in the superior collicullus and cerebellum. Neural Networks 2002;15:811-832. 